\title{
Language mapping in multilingual patients: electrocorticography and cortical stimulation during naming
}

\author{
Mackenzie C. Cervenka ${ }^{1}{ }^{*}$, Dana F. Boatman-Reich ${ }^{1}$, Julianna Ward ${ }^{2}$, Piotr J. Franaszczuk ${ }^{1}$ and Nathan E. Crone ${ }^{1}$ \\ Department of Neurology, Johns Hopkins University School of Medicine, Baltimore, MD, USA \\ 2 Department of Psychiatry and Behavioral Science, Johns Hopkins University School of Medicine, Baltimore, MD, USA
}

\section{Edited by:}

Olivier Bertrand, INSERM, France

Reviewed by:

Catherine Liegeois-Chauvel, INSERM,

France

Monica Baciu, Université Pierre

Mendès-France, France

*Correspondence:

Mackenzie C. Cervenka, Department of Neurology, Johns Hopkins University School of Medicine, Meyer 2-147,600 North Wolfe Street, Baltimore, MD

21287-7247, USA.

e-mail:mcerven1@jhmi.edu
Multilingual patients pose a unique challenge when planning epilepsy surgery near language cortex because the cortical representations of each language may be distinct. These distinctions may not be evident with routine electrocortical stimulation mapping (ESM). Electrocorticography (ECOG) has recently been used to detect task-related spectral perturbations associated with functional brain activation. We hypothesized that using broadband high gamma augmentation ( $\mathrm{HGA}, 60-150 \mathrm{~Hz}$ ) as an index of cortical activation, ECoG would complement ESM in discriminating the cortical representations of first (L1) and second (L2) languages. We studied four adult patients for whom English was a second language, in whom subdural electrodes (a total of 358) were implanted to guide epilepsy surgery. Patients underwent ECoG recordings and ESM while performing the same visual object naming task in L1 and L2. In three of four patients, ECoG found sites activated during naming in one language but not the other. These language-specific sites were not identified using ESM. In addition, ECOG HGA was observed at more sites during $L 2$ versus $L 1$ naming in two patients, suggesting that $L 2$ processing required additional cortical resources compared to $L 1$ processing in these individuals. Postoperative language deficits were identified in three patients (one in $L 2$ only). These deficits were predicted by ECoG spectral mapping but not by ESM. These results suggest that pre-surgical mapping should include evaluation of all utilized languages to avoid post-operative functional deficits. Finally, this study suggests that ECoG spectral mapping may potentially complement the results of ESM of language.

Keywords: multilingual, naming, electrocorticography, ECoG, high gamma, functional mapping, electrocortical stimulation mapping, epilepsy surgery

\section{INTRODUCTION}

Multilingual speakers are individuals who communicate routinely in more than one language and now outnumber monolingual individuals worldwide (French and Jacquet, 2004). However, predicting expected cortical language representations in these individuals can be challenging (Caramia et al., 1991). Studies comparing cortical maps of first (L1) and second (L2) language processing using a variety of imaging methods have provided heterogeneous results. These maps are important for planning neurosurgical resections to preserve L1 and L2 function. We used a novel technique of electrocorticographic (ECoG) spectral mapping to examine whether first and second languages are represented in distinct or common cortical regions in four adult patients undergoing intracranial language mapping for epilepsy surgery.

Language representations in multilingual patients have been studied using a variety of techniques including functional magnetic resonance imaging (fMRI; Dehaene et al., 1997; Kim et al., 1997; Marian et al., 2003, 2007; Perani et al., 2003; Wartenburger et al., 2003; Cheung et al., 2006; Meschyan and Hernandez, 2006; van Heuven et al., 2008; Chee, 2009; Ino et al., 2009; Marangolo et al., 2009), positron emission tomography (PET; Klein et al., 1994, 1995; Perani et al., 1998), functional near-infrared spectroscopy (fNIR; Kovelman et al., 2008), event-related potentials (Andreou and Karapetsas, 2001; Ceponiene et al., 2001; Alvarez et al., 2003;
Shestakova et al., 2003; Moreno and Kutas, 2005; Conboy and Mills, 2006; Khateb et al., 2007), and quantitative electroencephalography (EEG) analysis (Reiterer et al., 2005; Leinonen et al., 2007). Multilingual language organization has also been studied in patients with permanent structural lesions resulting from tumors or strokes (Aglioti and Fabbro, 1993; Gomez-Tortosa et al., 1995; Aglioti et al., 1996), or temporary functional lesions produced during language mapping with electrocortical stimulation (Ojemann and Whitaker, 1978; Rapport et al., 1983; Bellotti et al., 1991; Graff-Radford et al., 1997; Roux and Tremoulet, 2002; Lubrano et al., 2004; Roux et al., 2004; Walker et al., 2004; Giussani et al., 2007; Kho et al., 2007; Serafini et al., 2008; Moritz-Gasser and Duffau, 2009), transcranial magnetic stimulation (TMS; Holtzheimer et al., 2005), electroconvulsive therapy (Chernigovskaya et al., 1983), and Wada testing (Berthier et al., 1990; Kho et al., 2007).

Cortical mapping studies have yielded heterogeneous results regarding the organization of first (L1) and second (L2) languages (Caramia et al., 1991). Some studies have demonstrated complete overlap between the cortical representation of L1 and L2 within the dominant hemisphere, while others have demonstrated spatially distinct cortical representations of L1 and L2. While some electrocortical stimulation studies have demonstrated equivalent total cortical surface area involved in L1 and L2 processing, with partially overlapping regions (Graff-Radford et al., 1997; Roux and 
Tremoulet, 2002), others have shown increased cortical resources for L2 processing compared to L1 (Klein et al., 1994; Dehaene et al., 1997; Graff-Radford et al., 1997; Kim et al., 1997; Perani et al., 2003; Meschyan and Hernandez, 2006; Marian et al., 2007; Kovelman et al., 2008). Lesion studies have described patients who became aphasic in one language but not another as the result of a permanent structural lesion (Aglioti and Fabbro, 1993; Gomez-Tortosa et al., 1995; Aglioti et al., 1996), or a temporary functional lesion during Wada testing (Berthier et al., 1990; Kho et al., 2007), TMS (Holtzheimer et al., 2005), or intracranial electrocortical stimulation (van Heuven et al., 2008; Moritz-Gasser and Duffau, 2009). This evidence suggests that cortical representations for L1 and L2 include distinct regions.

Cortical regions have been found to be involved in both $\mathrm{L} 1$ and L2 processing within the dominant perisylvian cortex (Ojemann and Whitaker, 1978; Dehaene et al., 1997; Kim et al., 1997; Andreou and Karapetsas, 2001; Roux and Tremoulet, 2002; Marian et al., 2007; Serafini et al., 2008). However, studies have also identified regions involved in $\mathrm{L} 2$ processing alone in the dominant inferior frontal lobe (Ojemann and Whitaker, 1978; Kim et al., 1997; Roux and Tremoulet, 2002; Marian et al., 2003, 2007; Perani et al., 2003; Meschyan and Hernandez, 2006; Serafini et al., 2008), the dominant parietal cortex (Ojemann and Whitaker, 1978; Graff-Radford et al., 1997; Roux and Tremoulet, 2002; Meschyan and Hernandez, 2006; Serafini et al., 2008), the dominant posterior temporal region (Graff-Radford et al., 1997), and the non-dominant hemisphere (Dehaene et al., 1997; Cheung et al., 2006; Kovelman et al., 2008). Yet other studies have identified regions involved to a greater extent in $\mathrm{L} 1$ than $\mathrm{L} 2$ processing in the dominant temporo-parietal region (Perani et al., 1998) and in subcortical regions such as the dominant basal ganglia (Aglioti and Fabbro, 1993; Aglioti et al., 1996). Some of these distinctions in localization may reflect differences in the language tasks used.

In summary, previous functional neuroimaging studies, as well as studies of the effects of permanent structural lesions and temporary functional lesions, have shown evidence for complete overlap between L1 and L2 representations, while others have demonstrated L1-specific regions and L2-specific regions. Views of language organization have been developed to explain these cortical language representations. One view is that $\mathrm{L} 1$ and $\mathrm{L} 2$ processing recruit the same neural networks and that any differences in spatial representations are due to varying computational demands only (Perani and Abutalebi, 2005). Another view is that $\mathrm{L} 2$ acquisition is a dynamic process that depends on the age of language acquisition and the level of proficiency. During this process, people gradually progress from retrieving L1 words to acquire meaning in L2, to directly accessing word meaning in L2 (Wartenburger et al., 2003; Perani and Abutalebi, 2005; Abutalebi, 2008). This view predicts that proficient L2 speakers and those with an early age of acquisition ( $<7$ years) will have very similar or identical cortical language representations in L1 and L2. Conversely, less proficient speakers and/or with a later age of acquisition will have a larger region of cortex devoted to processing in $\mathrm{L} 2$ than to processing in L1 (Fabbro, 2001). These views do not explain why sites responsible for only L1 but not L2 processing have also been identified. One possible explanation for this observation is that neural networks involved in storing and utilizing linguistic parameters such as syntactic and grammatical regularities are distinct for L1 and L2, given that these parameters themselves are distinct for each language (Perani et al., 1998). Alternatively, some neural networks established to process L1 may be functionally specialized to such an extent that they cannot later be utilized during L2 processing. Other environmental factors may also contribute to patterns of early L1 and L2 acquisition (Genesee et al., 1995).

Accurate language mapping can be critical for planning epilepsy surgery. The location of the epileptogenic zone can affect language organization and in a language-dependent pattern (Cheung et al., 2006). Therefore, language localization may be influenced not only by the age of acquisition and level of proficiency, but also by the proximity of the epileptogenic zone to eloquent language cortex and the time of seizure-onset. These complex interactions could potentially lead to unpredictable patterns of language localization and may necessitate extensive and accurate language mapping to prevent post-operative language decline. Functional language mapping is usually performed with electrocortical stimulation through subdural electrodes implanted for seizure localization. The placement of these electrodes also allows for ECoG spectral mapping during functional brain activation. ECoG spectral mapping is an emerging technique for functional mapping of language and motor cortex. Broadband event-related power augmentation in high gamma frequencies $(>60 \mathrm{~Hz})$ has been shown to be an excellent index of cortical activation during language tasks, including visual object naming, auditory tone and phoneme discrimination, speech perception, and lexical-decision tasks (Crone et al., 1998a, 2001; Crone, 2000; Ray et al., 2003; Sinai et al., 2005a,b, 2009; Tanji et al., 2005; Brown et al., 2008; Towle et al., 2008). Few studies have directly compared postoperative outcomes following electrocortical stimulation mapping (ESM) versus ECoG spectral analysis (Sinai et al., 2005a; Towle et al., 2008), and it remains unclear which technique is a more sensitive predictor of potential post-operative language function.

In the current investigation, we studied four adult patients with intractable epilepsy who had acquired English as a second language relatively late ( $>6$ years; Wartenburger et al., 2003), and in whom subdural electrodes were implanted for epilepsy surgery over the dominant hemisphere. Based on results from the majority of functional neuroimaging studies reviewed here, we predicted that L1 and L2 cortical representations would include distinct cortical regions. Given that our patients acquired L2 at a later age, we predicted a greater cortical representation overall for L2 than for L1 naming, based on the dynamic view of language representation in second language learners (Wartenburger et al., 2003). We also predicted that ECoG spectral mapping would provide a more powerful means of directly comparing L1 and L2 than ESM. Patients underwent functional mapping with both techniques during a visual object naming task using pictures from the Boston Naming Test (BNT; Kaplan et al., 2001) in both L1 and L2. We used the BNT because normative data existed to compare performance in English and several other languages. Most documented postoperative language deficits involve a component of dysnomia and therefore, visual object naming tasks are most frequently used in ESM language batteries. Based on previous ESM and ECoG spectral mapping studies (Ojemann, 1979; Krauss et al., 1996; Anderson et al., 1999; Hamberger et al., 2001; Sinai et al., 2005a; Hamberger, 2007), visual object naming in English has been localized to the dominant posterior superior temporal gyrus, the mid and posterior 
temporal cortex, as well as basal temporal-occipital regions. Recent studies have suggested that additional cortical areas can be identified with ECoG spectral mapping that are not appreciated with ESM during visual naming (Sinai et al., 2005a; Thampratankul et al., 2010). Naming studies using fMRI and PET, including those in multilingual subjects, have identified much broader regions of cortical activation including bilateral occipital regions, fusiform gyri, cerebellar regions, and subcortical structures, not necessarily representing eloquent cortex (Votaw et al., 1999; Marangolo et al., 2009). We sampled dominant hemisphere cortex during both ESM and ECoG spectral mapping. We used within-subjects repeated measures testing to create time-frequency plots of ECoG spectral changes. We used a matching pursuit algorithm of signal decomposition to detect event-related power augmentation in high gamma frequencies $(60-150 \mathrm{~Hz})$ as a measure of language activation during L1 and L2 visual object naming.

Using ECoG spectral mapping, we identified L1 and L2-specific cortical regions as well as regions shared by both languages. The L1- and L2-specific regions were not identified by ESM. A greater number of electrodes revealed high gamma augmentation (HGA) during L2 versus L1 naming in two of four patients, suggesting that L2 processing required additional cortical resources compared to $\mathrm{L} 1$ processing in these patients. Post-operative naming deficits were identified, and these were predicted by ECoG spectral mapping of HGA but not by ESM, upon which resection margins were solely determined.

\section{MATERIALS AND METHODS PARTICIPANTS}

Four adult patients, ages 28, 31, 47, and 50 years, were identified for whom English was a second language (L2) and in whom subdural electrodes were implanted over the dominant hemisphere cortex for epilepsy surgery planning. This limited the number of participants that qualified to be included in the study. The study was approved by the Johns Hopkins Medicine Institutional Review Board, conformed to relevant regulatory standards, and informed consent was obtained from each patient during enrollment. All participants underwent extensive pre-operative neuropsychological evaluations in English. All patients first learned their native language (L1) and continued to use this language to communicate with family, then also began speaking English in the United States, and required the use of English to work and/or communicate with family and friends.

\section{Patient 1 ( L1 = lgbo)}

Patient 1 was a 28 -year-old right-handed Nigerian man who began having intractable complex partial seizures at age 24 years. An MRI revealed a non-enhancing left hippocampal mass lesion later identified as a gangliocytoma. Continuous video-EEG monitoring suggested a seizure focus in left temporal region. Language lateralization by intracarotid amobarbital injection (Wada test) found left hemisphere dominance for language in English and in Igbo and mild memory impairment with left-sided injection, deemed not sufficient to place the patient "at risk for a severe amnestic disorder". Given the proximity of the patient's lesion to anticipated eloquent language cortex, he underwent intracranial monitoring with grid electrodes prior to resection.
The patient lived in Nigeria as a child where he communicated and was educated in Igbo. He completed 14 years of education before immigrating to the United States as a teenager, and began working and speaking English daily with an accent but continues to communicate in Igbo with family.

\section{Patient 2 (L1 = Italian)}

Patient 2 was a 47-year-old right-handed man who began having intractable complex partial seizures at age 8 years. His presurgical volumetric MRI revealed left mesial temporal sclerosis. Continuous video-EEG monitoring identified seizures originating from the left anterior and midtemporal regions. Wada testing revealed left hemisphere dominance for language (tested only in English) and impairment of memory with both left and right injections. The patient underwent intracranial monitoring with grid electrodes prior to resection to verify the ictal-onset zone, given that two potential ictal-onset zones were identified during previous scalp monitoring.

The patient was raised in Sicily, Italy and completed 9 years of education in Italian. He immigrated to the United States at age 16 and began speaking English daily, with an accent. He owns and operates a restaurant in the United States and communicates in English with his customers but communicates in Italian with family.

\section{Patient 3 (L1 = Spanish)}

Patient 3 was a 31-year-old right-handed man who was struck (as a pedestrian) by a motor vehicle at 16 years of age and sustained a traumatic brain injury with basilar skull fracture, bifrontal intracranial hemorrhages, and prolonged loss of consciousness. He had no reported functional deficits following this injury but began having complex partial seizures 10 years later. An MRI revealed non-specific T2 and FLAIR hyperintensities within the anterior frontal lobes bilaterally. During continuous scalp videoEEG monitoring, seizures originated from left anterior temporalfrontal head regions but frequent bilateral epileptiform discharges were seen interictally. An interictal PET scan was not localizing. The patient underwent intracranial monitoring with bilateral strip electrodes and the ictal-onset zone was again localized to the left temporo-frontal region (Patient 3a). The electrodes were removed with no ESM or resection performed at that time. Wada testing revealed left hemisphere dominance for language and memory (tested only in English). The patient then underwent repeat intracranial monitoring with subdural electrodes to further localize the ictal-onset zone and to map functional cortex prior to resection (Patient $3 \mathrm{~b}$ ).

The patient was born in New York and raised by an aunt and uncle from El Salvador who spoke Spanish in the home. He began learning English in primary school but then moved to El Salvador at age 7 where he lived and attended school for a year before returning to the United States. On return, he attended English-as-a-second-language courses, completed 10 years of education in English, and then left school to begin working as a construction foreman. He speaks Spanish at work and is married to an English-speaking woman. He speaks only English with his wife and children in the home and does not have a Spanish accent. 


\section{Patient 4 (L1 = Greek)}

Patient 4 was a 50 -year-old ambidextrous woman who began having intractable complex partial seizures at age 31 years. Her pre-surgical MRI showed no abnormalities. Seizures captured during continuous scalp video-EEG monitoring originated from the left anterior temporal region. An interictal PET scan showed left temporal hypometabolism. Wada testing revealed left hemisphere dominance for language, and memory was impaired following both injections (tested only in English).

The patient was born in the Republic of Cyprus and first spoke Greek. She immigrated to the United States at age 10 and began learning English, speaking with an accent. She completed a master's degree in the United States in English, and worked until recently as a financial aid officer, communicating daily at work in English, and with her family in Greek.

\section{IMPLANTED ELECTRODES}

Subdural electrode arrays consisted of 1.5-mm-thick soft Silastic sheets (Ad-Tech, Racine, WI, USA) imbedded with platinumiridium disks (4-mm in diameter, 2.3-diameter exposed surface, 10-mm apart) of various configurations determined by the epilepsy and neurosurgical team based on previous neuroimaging, anatomical constraints, and EEG results. Electrode locations were determined by intra-operative photographs and co-registration of each patient's post-surgical CT to a pre-surgical volumetric MRI (1- to 1.8-mm coronal slice thickness; see also Crone et al., 1998b, 2001; Boatman and Miglioretti, 2005; Sinai et al., 2005a for a complete description of co-registration procedures).

\section{ELECTROCORTICAL STIMULATION MAPPING OF VISUAL OBJECT NAMING}

All patients underwent functional mapping with electrocortical stimulation of motor and language cortex following routine clinical procedures (Lesser et al., 1987; Sinai et al., 2005a). ESM was performed in 2- to 3-h blocks over 1-4 days. Electrode pairs were stimulated using a GRASS S-12 Biphasic Stimulator (Grass-Telefactor/Astro-Med, Inc., West Warwick, RI, USA). Intracranial EEG was continuously monitored for after-discharges and seizures. Two- to 5 -s trains of $50 \mathrm{~Hz}$, $0.3 \mathrm{~ms}$, alternating polarity square-wave pulses were delivered in $0.5-\mathrm{mA}$ increments from $1 \mathrm{~mA}$ up to a maximum of $12 \mathrm{~mA}$ (typically between 7 and $12 \mathrm{~mA}$ ), or the highest amperage that did not produce after-discharges at a given electrode pair, maximizing currents at each cortical site regardless of adjacent after-discharge thresholds (Lesser et al., 1984; Pouratian et al., 2004).

ESM was performed during a visual object naming task consisting of 40 black-and-white line drawings adapted from the BNT (Goodglass et al., 1983).Visual stimuli were presented individually on paper, and patients were instructed to name each item aloud as quickly as possible. Mapping was repeated with verbal responses in either L1 or L2 when possible. Adjacent electrode pairs were stimulated. Prior studies have indicated that maximal current density is immediately subjacent to each of the electrodes and that the effect of stimulation may occur at either electrode in the pair (Nathan et al., 1993). Tasks were performed with and without cortical stimulation, and performance was compared during the two conditions to identify interference in naming. Language location was determined as follows: electrode pairs were considered
$\operatorname{ESM}(+)$ for language if stimulation resulted in absent or delayed responses, paraphasic errors, and/or incorrect responses not followed by after-discharges during at least two trials at the same electrode pair, if these errors were not also present during baseline testing (Sinai et al., 2005a). For instance, if the patient provided a delayed response during stimulation when shown one stimulus then did not respond when shown another, the electrode pair being stimulated was considered $\operatorname{ESM}(+)$, provided that these errors were not also present during baseline testing of the same stimuli. If there was an interruption in naming during stimulation but none during after-discharges, the electrode pair was considered $\operatorname{ESM}(+)$. Otherwise, electrode pairs were defined as $\operatorname{ESM}(-)$ for naming, including if there were after-discharges as a result of stimulation, but no hesitation, interruption or incorrect response. If ESM at an electrode pair produced or interfered with involuntary movement, it was considered $\mathrm{ESM}(+)$ for motor function and was usually not tested for naming. If stimulation caused an unpleasant sensation, the electrode pair was also not tested for naming. ESM was also performed during additional receptive and expressive language tasks including paragraph reading, auditory sentence comprehension (modified Token Test), and spontaneous speech tasks, but these results were beyond the scope of the present study.

Electrocortical stimulation results were displayed on individual 3D MRI reconstructions for each patient to compare localization of motor and language functions with ECoG spectral mapping results. $\operatorname{ESM}(+)$ and $\operatorname{ESM}(-)$ electrode pairs were mapped for visual object naming in L1 and L2, and for motor function. Electrode pairs where ESM produced pain, seizures, and after-discharges were nevertheless included in passive ECoG recordings, which were not affected by these complications.

\section{ELECTROCORTICOGRAPHIC SPECTRAL MAPPING OF VISUAL OBJECT NAMING}

All patients received functional mapping with spectral analysis of ECoG signals recorded during visual object naming in L1 and in L2. The stimuli consisted of 60 to 85 distinct black-and-white line drawings derived from the BNT (Goodglass et al., 1983). Stimuli were presented individually one or more times on a computer monitor in a pseudorandomized order for each ECoG recording. Patients 1 and 2 were reviewed retrospectively, and named 85 stimuli in L2 before naming the same stimuli in L1 and visual stimuli were displayed until the onset of the verbal response. Patient 3 and 4 were studied prospectively. They were instructed to name 30 stimuli first in L1 and then in L2, again with pseudorandom presentation. Subsequently, 30 additional stimuli were named in L2 then in L1, again in random order. Stimuli were displayed for $1 \mathrm{~s}$. Patients were asked to fixate on a black cross on a white background between stimuli and were instructed to name items aloud as quickly as possible. If they were not immediately certain of the name of the pictured object, they were prompted to say "pass" in English or the equivalent word in their native language and proceed immediately to the next stimulus. Patients were instructed not to continue thinking of previous stimuli so that the baseline prior to stimulus presentation would not be contaminated by naming-related brain activation. Trials were discarded if the patient responded incorrectly, 
"passed", responded during the 1-s pre-stimulus baseline, did not respond, or if there was any distraction in the room, unsolicited patient speech, or significant patient movement during the trial. A marker for stimulus-onset time was digitally recorded using a photodiode and verbal responses were monitored with a voice trigger or a microphone. When possible, a 30- to 60-item BNT was repeated post-operatively in L1 and in L2 using line drawings on paper. The verbal responses were recorded and the times to verbal response from stimulus presentation (RT) were measured.

\section{DATA ANALYSIS}

\section{Performance on the BNT in L1 and L2}

The number of correct verbal responses on the BNT was compared to available normative data from a meta-analysis of 33 previous English BNT studies (Mitrushina et al., 2005). No BNT normative data was available for Igbo or Italian. However, three studies provided BNT normative data in Spanish: (1) for Spanish speakers (Ponton et al., 1996); (2) for Spanish/English speakers (Kohnert et al., 1998; Rosselli et al., 2000) comparing Spanish and English performance; and (3) for Spanish/English speakers, examining English performance alone (Roberts et al., 2002). One study provided BNT normative data in Greek (Patricacou et al., 2007). Z-scores were calculated using these normative data and reported as percentiles for each patient in English and for Patient 3 in English and in Spanish. Verbal response times (RT) were recorded, mean and median RT were calculated, and mean RT were compared between L1 and L2 in each patient using a paired $t$-test $(p<0.05)$.

\section{Electrocorticographic spectral mapping}

ECoG signals were amplified and digitally recorded using an intracranial referential montage at a sampling rate of $1000 \mathrm{~Hz}$ and a bandwidth of $0.3-300 \mathrm{~Hz}$ along with marker channels for stimulus onset and offset. Reference electrodes were selected over relatively inactive cortical regions at a corner of the electrode array. Signals were then re-montaged to an average reference to minimize the contribution of activity at the reference electrode (Crone et al., 2001). The digital recording was inspected by a trained epileptologist (MCC) to exclude electrodes from analysis if the electrographic signal was contaminated by artifact, and individual trials if they contained frequent epileptiform discharges. The signal was then low-pass filtered to $250 \mathrm{~Hz}$ and down-sampled by a factor of 2 .

ECoG signals were averaged over 28 to 84 trials (correct responses only) for event-related changes in the ECoG power spectrum with attention to broadband high gamma event-related activity $(60-150 \mathrm{~Hz})$ as broadband HGA has been shown to be a reliable index of cortical activation (Crone et al., 2006). We used a time-frequency matching pursuit algorithm for signal decomposition (Mallat and Zhang, 1993; Franaszczuk et al., 1998; Ray et al., 2003; Sinai et al., 2005a, 2009; Boatman-Reich et al., 2010) which provides improved time-frequency resolution compared to traditional Fourier transform and wavelet transform methods of signal analysis (Zygierewicz et al., 2005; Durka, 2006; BoatmanReich et al., 2010). Time-frequency decomposition by matching pursuits was performed on segments of ECoG that included a pre-stimulus interval of $1000 \mathrm{~ms}$ and a post-stimulus onset interval of $3000 \mathrm{~ms}$. An 800-ms portion of the pre-stimulus baseline
$(-100$ to $-900 \mathrm{~ms})$ was used to calculate power changes relative to the baseline and compared for statistical significance to the first $2000 \mathrm{~ms}$ following stimulus-onset. Signal components representing power line noise (60 and $120 \mathrm{~Hz}$ ) were excluded from spectral power analysis. Baseline power was computed by averaging over all baseline points and all trials. Power for each post-stimulus time point was computed by averaging over all trials. Significant eventrelated power changes were identified by comparing post-stimulus time-frequency points to baseline frequency points using a twosided $t$-test $(p=0.05)$ after logarithmic transformation, assuming unequal variance (Zygierewicz et al., 2005). A false discovery rate control $(q=0.05)$ was applied to correct for multiple comparisons (Durka et al., 2004). The magnitudes of statistically significant power changes were plotted with respect to time and frequency. Electrodes that revealed statistically significant HGA $(60-150 \mathrm{~Hz})$ were defined as $\mathrm{HGA}(+)$ sites and electrodes that revealed no statistically significant HGA were defined as $\mathrm{HGA}(-)$ sites.

To test the null hypothesis that there was no difference between the number of $\mathrm{HGA}(+)$ electrodes during L1 and L2 visual object naming, we used a two-sided McNemar's test for paired samples $(p<0.05)$. For each patient, $2 \times 2$ contingency tables were computed, based on the total number of electrodes tested, and exact binomial probability calculations were performed.

\section{Comparing ESM and ECoG spectral maps of naming to post-operative outcomes}

ECoG spectral mapping of visual object naming was designed to produce a statistically significant map of L1 and L2 naming. To determine the clinical significance of these findings, individual $3 \mathrm{D}$ post-operative reconstructions were created and pre-operative electrode arrays were superimposed on the post-operative image to identify electrodes that had been removed during surgery. $\operatorname{ESM}(+), \operatorname{ESM}(-), \mathrm{HGA}(+)$ and $\mathrm{HGA}(-)$ electrodes for visual object naming in L1 and L2 were identified that were preserved and resected.

\section{RESULTS PRE-OPERATIVE NEUROPSYCHOLOGICAL EVALUATIONS}

In Patient 1, results of pre-operative neuropsychological assessment revealed low average to average range performance on verbal measures including measures of verbal memory in English. Patient 2 did not have formal IQ scores reported and verbal abilities were within the average range in English. Verbal memory performance was in the low average to average range. In Patient 3, pre-operative neuropsychological assessment in English revealed generally low average to average range verbal abilities, with the exception of spelling, but borderline to low average memory performance. Patient 4 had borderline to average performance on verbal measures and low to borderline verbal memory performance in English (Table 1). All patients tested had below average IQ scores, which may have been artificially lowered due to formal testing in English (L2).

\section{ELECTROCORTICAL STIMULATION MAPPING}

A total of 107 electrode pairs were assessed for language and motor function with ESM. Of these, 18 were $\operatorname{ESM}(+)$ for visual object naming, located in frontal, temporal and/or parietal regions in 
Table 1 | Pre-operative neuropsychological assessment in English (L2) for all patients.

\begin{tabular}{|c|c|c|c|c|}
\hline Study & Patient 1 & Patient 2 & Patient 3 & Patient 4 \\
\hline \multicolumn{5}{|c|}{ Wechsler Adult Intelligence Scale (WAIS-Ra; WAIS-III ${ }^{b}$ ) } \\
\hline Full-Scale IQ & $69\left(2 \text { nd }^{* 1-2}\right)^{\mathrm{a}}$ & "Impaired attention, & $75\left(5 \text { th }^{* 2}\right)^{b}$ & $81\left(10 \text { th }^{* 3}\right)^{\mathrm{b}}$ \\
\hline Verbal IQ & $68\left(2 \mathrm{nd}^{* 1-2}\right)^{\mathrm{a}}$ & concentration, writing, & $75\left(5 \text { th }^{* 2}\right)^{b}$ & $85\left(16 \text { th }^{* 3}\right)^{\mathrm{b}}$ \\
\hline Performance IQ & $73(4 \text { th } * 2)^{a}$ & arithmetic"a & $79\left(8 \mathrm{th}^{* 2}\right)^{\mathrm{b}}$ & $79\left(8 \operatorname{th}^{* 2}\right)^{\mathrm{b}}$ \\
\hline \multicolumn{5}{|c|}{ Wide Range Achievement Test - 4th Edition (WRAT) ${ }^{c}$} \\
\hline Spelling skills & & & $3 r d^{* 2}$ & $61 \mathrm{st}^{* 4}$ \\
\hline Verbal Fluency Test (FAS) ${ }^{d}$ & 11 th $^{* 3}$ & $34 \mathrm{th}^{* 4}$ & 24 th-71st ${ }^{* 3-4}$ & $3 \mathrm{rd}^{* 2}$ \\
\hline Spontaneous Speech & Fluent & & & \\
\hline Writing Skills & Average & & & \\
\hline \multicolumn{5}{|l|}{ Verbal Memory Measure (RAVLTe; HVLT-R') } \\
\hline Overall learning & $21 s t * 3 e$ & 58 th $^{* 4 \mathrm{e}}$ & $16 \mathrm{th}^{* 3 f}$ & $4 \operatorname{th}^{* 2 f}$ \\
\hline Delayed recall & $38 \mathrm{th}^{* 4 \mathrm{e}}$ & $10 \operatorname{th}^{* 3 \mathrm{e}}$ & $4 \mathrm{th}^{* 2 f}$ & $<1 s t^{* 1 f}$ \\
\hline Verbal memory performance & Low average to average & Low average to average & Borderline to low average & Low to borderline \\
\hline
\end{tabular}

Percentiles (*) and corresponding performance ranges are included (Mitrushina et al., 2005).

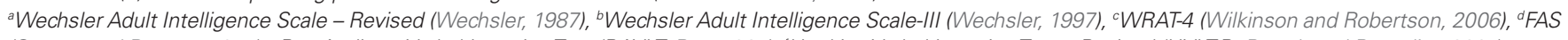
(Spreen and Benton, 1977), ${ }^{e}$ Rey Auditory Verbal Learning Test (RAVLT; Rey, 1964), ${ }^{f}$ Hopkins Verbal Learning Test - Revised (HVLT-R; Brandt and Benedict, 2001).

'Extremely low performance, ${ }^{2}$ Borderline performance, ${ }^{3}$ Low average performance, ${ }^{4}$ Average performance.

all patients, and in anterior and basal temporal regions in Patient 3 (Figure 1). All four patients had regions where ESM could not be completed because stimulation provoked pain. In Patient 3 , one electrode pair could not be tested due to stimulation-induced after-discharges. In Patient 4, naming was performed in L2 only. Testing was aborted early to prevent seizure provocation after stimulation produced frequent and prolonged after-discharges at four electrode pairs. Mapping of visual object naming was identical in L1 and L2 for Patients 1 and 2 (Figures $\mathbf{1 A}, \mathbf{B}$ ), and a single electrode pair within the dominant inferior frontal gyrus was identified in Patient 3 that was ESM(+) for L2 naming but not L1 naming (Figure 1C).

\section{PERFORMANCE ON THE BNT IN L1 AND L 2}

Performance on the 60-item BNT in L1 and L2 during ECoG recordings varied between patients (Table 2). Patient $1(\mathrm{~L} 1=$ Igbo) provided more correct responses to stimuli in L1 (61\%) than in L2 (41\%) and the RT were not significantly different. Patient $2(\mathrm{~L} 1=$ Italian) provided more correct responses in L1 (99\%) than in L2 (93\%) and the RT was significantly longer for L2 than in L1 $(p<0.05)$. Patient $3(\mathrm{~L} 1=$ Spanish $)$ provided correct responses for nearly the same number of stimuli in L1 and L2 (80 and 77\%, respectively) during the first session of testing and the second session (77 and $82 \%$, respectively) with no significant difference in the RT during either session. Patient $4(\mathrm{~L} 1=$ Greek $)$ demonstrated poor performance on both tasks and provided more correct responses in L2 (53\%) than in L1 (47\%). There was no significant difference in the RT between tasks.

\section{ELECTROCORTICOGRAPHIC SPECTRAL MAPPING}

During ECoG spectral mapping, a total of 358 electrodes were assessed, and 81 revealed significant HGA in the frequency range of $60-150 \mathrm{~Hz}$ (Table 3). In all patients, the majority of HGA(+) electrodes revealed HGA during both L1 and L2 naming. In two patients (Patients 1 and 3 ), all HGA $(+)$ sites during L1 naming were also $\mathrm{HGA}(+)$ during $\mathrm{L} 2$ naming, and additional $\mathrm{HGA}(+)$ sites were identified during L2 naming only. In one patient (Patient 2), L1 - and L2-specific $\mathrm{HGA}(+)$ sites were identified as well as L1- and L2-shared regions. In one patient (Patient 4), L1 and L2 sites were identical.

In Patient 1, 16 electrodes were HGA(+) during L2 visual object naming and of these, only a subset (56\%) of the electrodes within posterior temporal and temporo-occipital regions were $\mathrm{HGA}(+)$ during $\mathrm{L} 1$ naming and no $\mathrm{HGA}(+)$ regions were unique to $\mathrm{L} 1$ (Figure 2A). In Patient 2, 16 (67\%) electrodes were HGA(+) during both L1 and L2 naming. Four (17\%) sites were HGA(+) during L1 naming only, and four (17\%) sites were unique to L2 (Figure 2B). In Patient 3a, 20 electrodes were HGA(+) during L1 and/or L2 naming (Figure 2C). Twelve sites were identified over the left, and eight sites were identified over right frontal and temporal regions. Of the $\mathrm{HGA}(+)$ sites, $14(70 \%)$ sites were $\mathrm{HGA}(+)$ during $\mathrm{L} 1$ naming and all 20 sites were $\mathrm{HGA}(+)$ during L2 naming. Note that ESM was not performed at any of these sites because the strip electrodes were implanted solely to identify the patient's ictal focus. In Patient 4, 8 electrodes were identified as $\mathrm{HGA}(+)$ for naming and all sites were $\mathrm{HGA}(+)$ during both L1 and L2 naming. Sites were identified in both perisylvian and basal temporal regions (Figure 2D). 

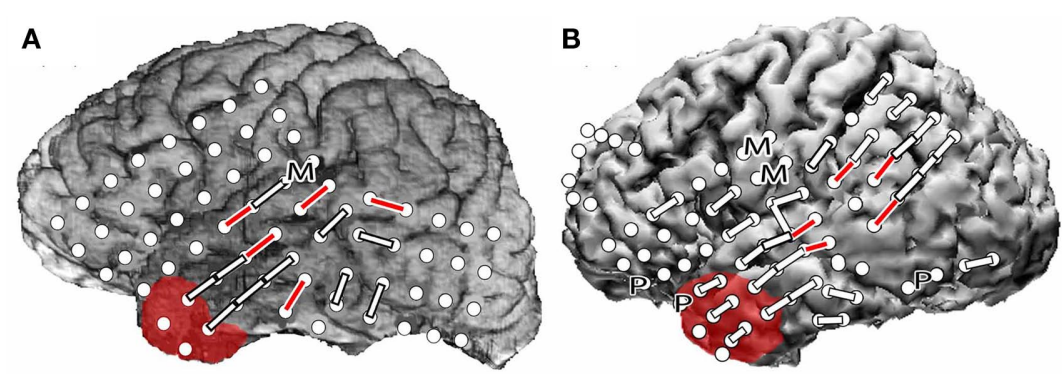

Figure Legend

$$
\begin{array}{ll}
- & =\operatorname{ESM}(+) \text { for naming } \\
\square & =\operatorname{ESM}(-) \\
\mathrm{M} & =\mathrm{ESM}(+) \text { for motor activity } \\
\mathrm{L} 2 & =\mathrm{ESM}(+) \text { for L2 naming } \\
\mathrm{P} & =\text { Pain } \\
\mathrm{A} & =\text { After-discharges } \\
\square & =\text { Ictal-onset zone }
\end{array}
$$
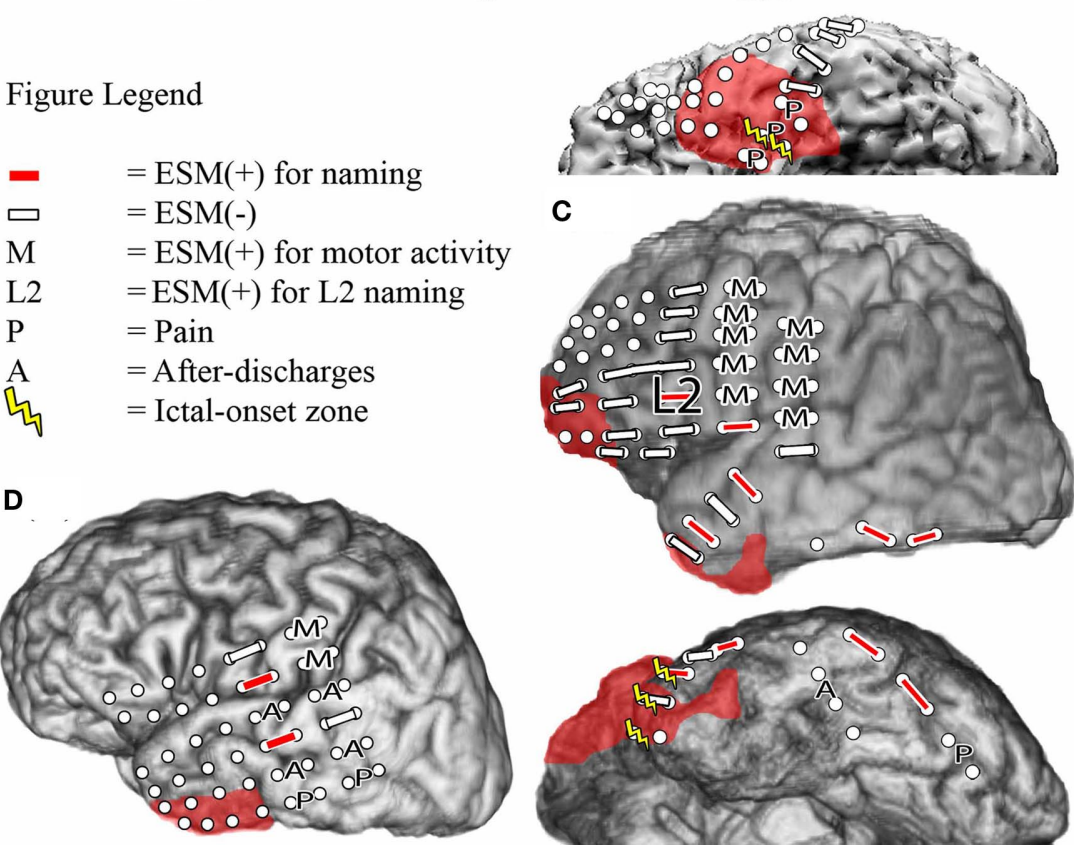

FIGURE 1 | Bipolar electrocortical stimulation mapping of visual object naming of L1 and L2 in Patient 1 (A), Patient 2 (B), and Patient 3b (C), and only in L2 in Patient 4 (D) using co-registration of a post-surgical CT with pre-surgical MRI to determine electrode placement. Left lateral and left basal views are shown when

applicable. White circles indicate the locations of the implanted subdural electrodes. In Patients 1 and 4, the ictal-onset zone was in the left mesial temporal region and is not depicted. Areas with red shading indicate the resection boundaries. No basal temporal ESM was performed in these patients, so basal views are not included.

Table 2 | BNT scores (number and percent correct) during ECoG spectral mapping, Z-scores compared to published normative data, mean \pm SD and median time to verbal responses from the onset of stimulus presentation (RT), and two-sided $t$-tests comparing first and second language RT.

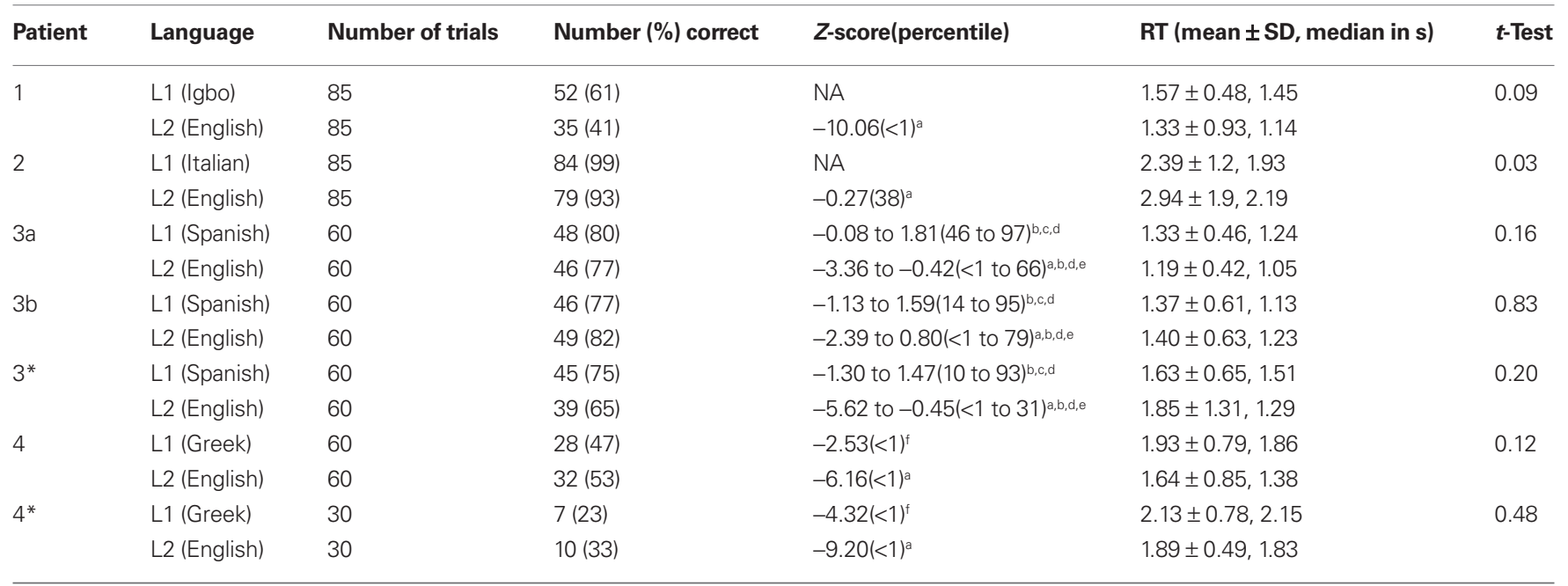

a Mitrushina et al. (2005), 'bRosselli et al. (2000), cPonton et al. (1996), dKohnert et al. (1998), e Roberts et al. (2002), fPatricacou et al. (2007), "Post-operatively. 
Table 3 | Electrodes (sites) with statistically significant HGA during visual object naming in first (L1) and second (L2) languages. $p$ Values comparing number of $\mathrm{HGA}(+)$ sites during $L 1$ and $L 2$ naming within patients using the McNemar's test.

\begin{tabular}{|c|c|c|c|c|c|c|}
\hline Patient & Sites tested & HGA(+) & $H G A(+)$ for $L 1$ and $L 2$ & HGA(+) for only L1 & HGA(+) for only L2 & $p$-Values \\
\hline 1 & 59 & 16 & 9 & 0 & 7 & 0.02 \\
\hline 2 & 87 & 24 & 16 & 4 & 4 & 1.00 \\
\hline $3 b$ & 78 & 13 & 8 & 0 & 5 & 0.06 \\
\hline 4 & 53 & 8 & 8 & 0 & 0 & 1.00 \\
\hline
\end{tabular}
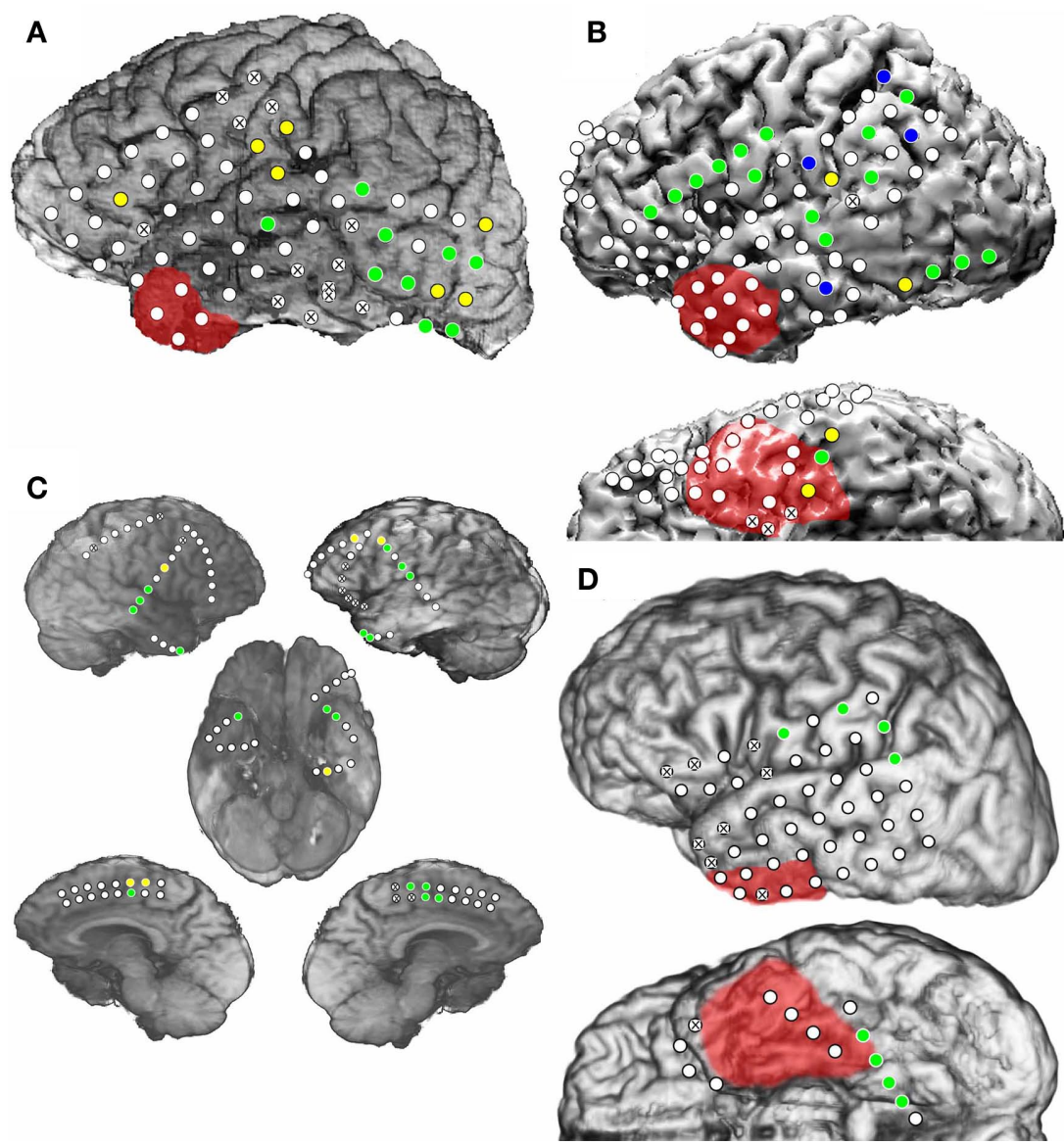

FIGURE 2 | Electrocorticographic spectral mapping of visual object naming in L1 and L2 in Patient 1 (A), Patient 2 (B), Patient 3a (C), and Patient 4 (D). Lateral, interhemispheric and basal views are shown when applicable. Electrodes used as ground or reference electrodes and those containing electrode artifact are indicated with an "X." Blue circles indicate HGA(+) electrodes during only L1 visual object naming. Yellow circles indicate HGA(+) electrodes during only L2 visual object naming. Green circles indicate HGA(+) electrodes during both L1 and L2 naming. As in Figure 1, areas with red shading indicate resection boundaries.
In Patient 3b, 13 sites revealed significant HGA and of these, $8(62 \%)$ sites were $\mathrm{HGA}(+)$ during L1 naming, and all sites were HGA(+) during L2 naming. Again, no sites were identified that were specific for L1 naming alone. Sites that were HGA(+) only during L2 naming were present in the anterior temporal tip, the superior temporal gyrus, and near the precentral gyrus (Figure 3). Two perisylvian electrodes were in nearly identical positions during the two intracranial recording sessions in Patient 3 , and these were $\mathrm{HGA}(+)$ during $\mathrm{L} 1$ and $\mathrm{L} 2$ visual object naming during both recording sessions. All other electrode positions in the second recording session did not overlap with locations of electrodes during the first recording.

For Patients 1 and 3a, a two-sided McNemar's test rejected the null hypothesis that the same number of electrodes were $\mathrm{HGA}(+)$ during L1 and L2 naming ( $p=0.02$ and 0.03 , respectively). The difference approached but did not reach significance in Patient 


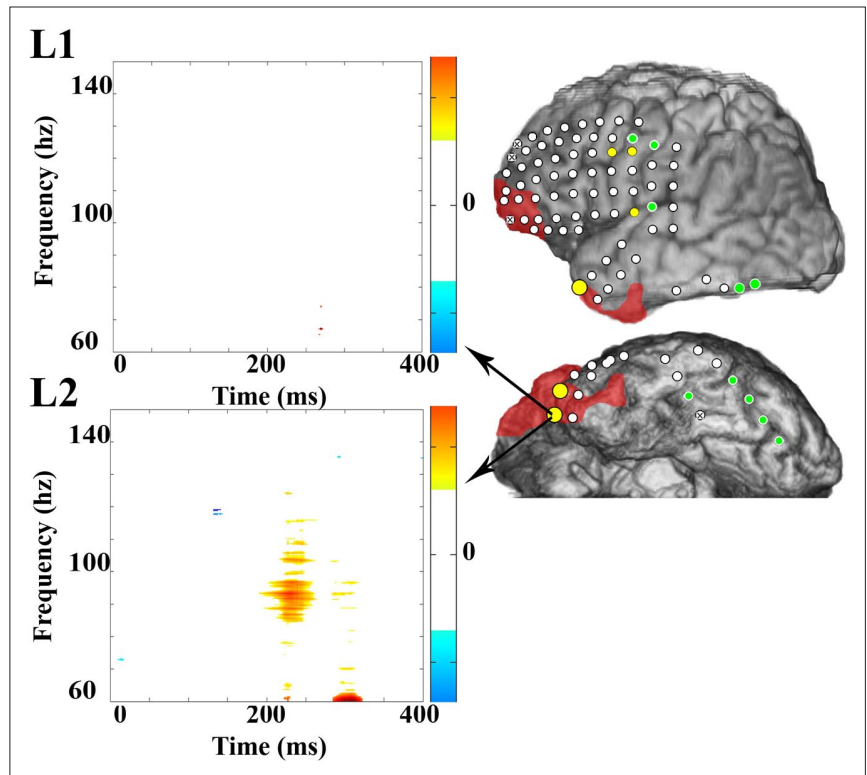

FIGURE 3 | Electrocorticographic spectral mapping of visual object naming in L1 and L2 in Patient 3b. Electrode color schemes are the same as in Figure 2. $\mathrm{HGA}(+)$ electrodes that were over regions that were ultimately resected are enlarged for emphasis. Time-frequency plots of changes in power obtained with MP analysis are shown for one selected anterior temporal electrode that was HGA(-) for L1 (top) and HGA(+) for L2 (bottom) and was over a region that was ultimately resected. Time zero on the $X$-axis is the time of stimulus onset. On the color spectrum depicted to the right of each plot, red to yellow indicates a significant increase in magnitude of power after stimulus-onset relative to the baseline within a given time (in $\mathrm{ms}$ )-frequency (in $\mathrm{Hz}$ ) range, and the spectrum from light to dark blue indicates a significant decrease in power. White indicates no significant difference.

$3 \mathrm{~b}(p=0.06)$, possibly because of the large number of electrodes that did not reveal significant HGA during either task. There was no difference in the number of HGA(+) electrodes for L1 and L2 naming in Patient 2 or Patient $4(p=1)$.

\section{ECOG SPECTRAL MAPPING VERSUS ESM OF VISUAL OBJECT NAMING}

Overall, 171 electrodes were assessed in four patients using both ECoG spectral mapping and ESM of visual object naming and mouth-related motor function and of those, 53 of $64 \operatorname{ESM}(+)$ electrodes were also $\mathrm{HGA}(+)$ for naming or immediately adjacent to sites that were $\mathrm{HGA}(+)$ for naming (Figures 1-3; Table 4). Ninety-five electrodes were $\operatorname{ESM}(-)$, and of these, 81 were $\mathrm{HGA}(-)$ during naming. In Patient 1, the majority of $\mathrm{HGA}(+)$ sites were located in the posterior temporal and occipital regions, many of which were not assessed with ESM (Figures 1A and 2A). In Patient 2, superior temporal and inferior parietal sites were identified with ESM, but additional supplementary language sites were revealed using ECoG spectral mapping, located within frontal and inferior and basal temporal regions (Figures $1 B$ and 2B). A single L2 specific region was identified with ESM in Patient 3. This site was not sampled during the first electrode implantation (Patient 3a; Figures $1 \mathrm{C}$ and 2C), and both electrodes within the pair were $\mathrm{HGA}(-)$ for both L1 and L2 naming during the second implantation (Patient 3b; Figures 1C and 3).
Table 4 | Location of L1 and L2 ECoG spectral responses and ESM results by Brodmann area (BA).

\begin{tabular}{|c|c|c|c|c|c|}
\hline \multirow[b]{2}{*}{ Patient } & & \multicolumn{2}{|c|}{ ECoG - BA(n) } & \multicolumn{2}{|c|}{$\operatorname{ESM}-\mathrm{BA}(n)$} \\
\hline & & L1 & L2 & L1 & L2 \\
\hline \multirow[t]{7}{*}{1} & $\mathrm{~F}$ & - & $2,5,6,46$ & NT, NT-M & NT, NT-M \\
\hline & & - & - & $44-44$ & $44-44$ \\
\hline & $\mathrm{T}$ & 22 & 22 & $22-22(2)$ & $22-22(2)$ \\
\hline & & NT & NT & $21-21$ & $21-21$ \\
\hline & & $37(3)$ & $37(3)$ & NT & NT \\
\hline & $P$ & 39 & 39 & $39-39$ & $39-39$ \\
\hline & $\mathrm{O}$ & $19(4)$ & $19(7)$ & NT & NT \\
\hline \multirow[t]{14}{*}{2} & $\mathrm{~F}$ & $\begin{array}{l}4(3) \\
6,44(2)\end{array}$ & $\begin{array}{l}4(3) \\
6,44(2)\end{array}$ & NT, NT-M & NT, NT-M \\
\hline & & 46 & 46 & - & - \\
\hline & $\mathrm{T}$ & 21 & - & - & - \\
\hline & & 22 & 22 & $22-22$ & $22-22$ \\
\hline & & - & $36^{*}$ & NT-Pn* & NT-Pn* \\
\hline & & - & - & $37-37$ & $37-37$ \\
\hline & & 37 & 37 & - & - \\
\hline & & - & 37 & - & - \\
\hline & & 37 & $37(2)$ & NT-Pn & NT-Pn \\
\hline & & 42 & 42 & $42-42$ & $42-42$ \\
\hline & $P$ & $2,7(3), 39$ & $7(2)$ & - & - \\
\hline & & 39 & 39 & $39-39$ & $39-39$ \\
\hline & & - & 40 & $40-40$ & $40-40$ \\
\hline & $\mathrm{O}$ & $19(2)$ & $19(2)$ & - & - \\
\hline \multirow[t]{11}{*}{$3 b$} & $\mathrm{~F}$ & $4(2)$ & $4(4)$ & NT-M & NT-M \\
\hline & & - & 6 & $6-43$ & $6-43$ \\
\hline & & - & - & - & $44-44$ \\
\hline & $\mathrm{T}$ & 20 & 20 & NT-A & NT-A \\
\hline & & - & - & $21-22$ & $21-22$ \\
\hline & & & & $37-37$ & 37-37, \\
\hline & & & & $38-38 *$ & $38-38^{*}$ \\
\hline & & $37(2)$ & $37(2)$ & $37-37$ & $37-37$ \\
\hline & & - & $38(2) *$ & - & - \\
\hline & & $41^{* *}$ & $41^{* *}$ & NT-M & NT-M \\
\hline & $\mathrm{O}$ & $19(2)$ & $19(2)$ & NT-Pn & NT-Pn \\
\hline \multirow[t]{6}{*}{4} & $\mathrm{~F}$ & - & - & NT & $6-43$ \\
\hline & & 6 & 6 & NT & - \\
\hline & $\mathrm{T}$ & - & - & NT & $22-22$ \\
\hline & & $37(2)$ & $37(2)$ & NT & NT \\
\hline & $P$ & $40(3)$ & $40(3)$ & NT & NT- M, A \\
\hline & $\mathrm{O}$ & $19(2)$ & $19(2)$ & NT & NT \\
\hline
\end{tabular}

All ECOG HGA(+) electrodes are listed by BA within each lobe and by number (n) of electrodes if greater than one. All ESM (+) electrodes are listed as electrode pairs by $B A$ and number (n) of pairs. Electrodes over cortical regions that were resected are in bold.

*Electrodes adjacent to ictal-onset zone, **same location during $3 a$ and $3 b$ testing, $F=$ frontal,$T=$ temporal,$P=$ parietal,$O=$ occipital,$N T=$ not tested, $M=$ motor, $A=$ after-discharges, $P n=$ pain,$-=$ negative for $L 1$ or $L 2$.

During the second implantation (Patient 3b), two electrodes near the anterior temporal tip were $\mathrm{HGA}(+)$ for L2 only (Table 4). One was $\operatorname{ESM}(-)$. An adjacent and more anterior electrode was HGA(+) for L2 only as well but was not tested with ESM. Patient 
4 received limited ESM in L2 only (Figure 1D). ECoG spectral mapping revealed $\mathrm{HGA}(+)$ perisylvian, as well as, basal temporal regions that were not tested with ESM (Figure 2D). Overall, ECoG mapping revealed a broader distribution of L1 and L2 naming sites than ESM, and frequently $\mathrm{HGA}(+)$ basal sites were not identified with ESM (Table 4).

\section{SEIZURE LOCALIZATION AND POST-SURGICAL OUTCOMES}

During intracranial monitoring, Patient 1 had complex partial seizures originating from the left mesial temporal lobe, anterior to the identified mass lesion. He underwent a left anterior temporal lobectomy with amygdalohippocampectomy and with a posterior resection margin $4.5 \mathrm{~cm}$ posterior to the temporal pole. No electrodes that were $\operatorname{ESM}(+)$ or $\mathrm{HGA}(+)$ during visual object naming were resected (Figures 1A and 2A). Pathology results were consistent with a gangliocytoma. Five years following excision, a follow-up MRI revealed no evidence of residual tumor and the patient was seizure-free off of all antiepileptic medication with no reported immediate or remote motor or language deficits. He was then lost to follow-up.

In Patient 2, intracranial monitoring confirmed a seizure focus over the left anterior mesial temporal region. He underwent a left temporal lobectomy with amygdalohippocampectomy, sparing regions found to be eloquent for language based on ESM results (Figure 1B). Two HGA(+) sites during naming within the dominant basal temporal region were resected, one that was $\mathrm{HGA}(+)$ during L1 naming only and one that was HGA(+) during L1 and L2 naming (Figure 2B). Pathology results showed severe neuronal loss and reactive astrocytosis in area CA1 consistent with left mesial temporal sclerosis. The patient is now 9 years postresection and has had only one post-operative seizure after his phenytoin was changed from brand name to a generic preparation without his knowledge. Based on review of the medical chart, this patient was described on post-operative Days 1 through 5 as having a mild to moderate anomia for objects with intact naming of body parts, as well as impaired verbal memory with intact comprehension in L2. No mention was made of any evaluation in L1. These deficits were "slightly" improved but did not resolve prior to discharge. No mention was made of any residual longterm deficits.

During the second admission for intracranial monitoring, Patient 3's ictal-onset zone was localized to the left anterior temporal tip. The resection included this region, excluding areas identified by ESM as eloquent (Figure 1C), as well as a portion of the adjacent inferior frontal region where significant interictal activity was also observed. Two $\mathrm{HGA}(+)$ sites during L2 visual object naming, but not L1 visual object naming, were resected (Figure 3). ECoG mapping results at these sites were not taken into account when planning surgery because they were considered investigative. Additionally, these sites were included in the ictal-onset zone, the locations of these sites were considered atypical for sites essential for language function, and ESM at these electrodes did not interfere with language function. On post-operative Day 1, Patient 3 repeated the 60-item BNT in $\mathrm{L} 1$ and in L2. RT (verbal response times) were not significantly different for L1 and L2 ( $p=0.20)$. However, the number of correct responses decreased from 49 to 39 (17\% decline) during L2 naming and only from 46 to 45 (2\% decline) during L1 naming post-operatively compared to pre-operatively. The patient provided incorrect or no responses to 11 items that he had identified correctly pre-operatively, even after stimulus and phonemic cueing. He did not recognize one of the words even after being provided with the correct response.

Patient 4's ictal-onset zone was identified within the left hippocampus. She received a left anterior temporal lobectomy with amygdalohippocampectomy, sparing all $\operatorname{ESM}(+)$ regions, but ESM was extremely limited by frequent after-discharges, so only few electrodes were assessed. However, the basal temporal resection included regions covered by two electrodes that were $\mathrm{HGA}(+)$ for L1 and L2 naming (Figure 2D). On post-operative Day 4, Patient 4 repeated a 30 -item BNT in L1 and L2. RT were not significantly different between L1 and L2 ( $p=0.48)$. However, the percent of correct L1 responses decreased by $24 \%$, and the percent correct L2 responses decreased by $20 \%$. The patient responded incorrectly or provided no responses to 10 items in L1, and to 5 items in L2, that she had correctly identified preoperatively. Note that in Patients 3 and 4, decline in performance was observed despite possible practice effects from repeated use of the same stimuli.

\section{DISCUSSION}

We report the results of ECoG spectral mapping and ESM of visual object naming in four patients for whom English is a second language. We hypothesized that ECoG spectral mapping of HGA would identify distinct as well as shared cortical regions involved in first (L1) and second (L2) language visual object naming. Comparison of the spatial distribution of ECoG HGA during visual object naming in $\mathrm{L} 1$ and $\mathrm{L} 2$ revealed both shared as well as distinct regions of cortical HGA in three patients. Two patients showed significantly more electrodes with HGA during L2 than during L1 visual object naming. In one patient, the number of distinct sites was equal for L1 and L2 naming. In another patient, ECoG HGA cortical representations of L1 and L2 were identical. Overall, these findings support the hypothesis that language processing in L1 and L2 can involve distinct cortical regions.

Interestingly, ESM did not reveal differences in the spatial representations of L1 and L2 visual object naming in two patients (one did not receive ESM in $\mathrm{L} 1$ and $\mathrm{L} 2$ ), while differences were seen in three patients using ECoG spectral mapping of HGA. Three patients received resections that resulted in post-operative language deficits. One patient received an anterior temporal lobe resection that included regions identified as being involved in L2 visual object naming but not in L1 naming based on ECoG spectral mapping results. Although these regions were deemed safe for resection by ESM, the patient exhibited a decline in L2 visual object naming performance with preservation of L1 naming when assessed the day following surgery. In another patient, ESM was limited by frequent after-discharges so testing was extremely limited. ECoG spectral mapping revealed basal temporal L1 and L2 naming areas that were resected and the patient had a post-operative deficit in naming in both languages. These results suggest that ECoG spectral mapping correctly identified regions of eloquent language cortex not found by ESM. 


\section{ESM OF VISUAL OBJECT NAMING IN L1 AND L2}

In this study, electrocortical stimulation in the left inferior frontal region inhibited visual object naming in $\mathrm{L} 2$, but not in $\mathrm{L} 1$, in a single patient but otherwise, no differences were found between mapping of L1 and L2 naming. The majority of ESM studies on multilingual patients have demonstrated differential effects on L1 and L2 processing during stimulation at one or more cortical regions, while others have showed no difference. Ojemann and Whitaker (1978) described two early reports of patients in which ESM interfered with naming in two languages in some regions and in each language separately in other areas. Roux and Tremoulet (2002) demonstrated language- and task-specific cortical areas during reading, counting, and word retrieval tasks in 7 of 12 bilingual or multilingual patients undergoing ESM for brain tumor resection. Lucas et al. (2004) mapped visual object naming in 25 patients and demonstrated differences in the spatial distribution of L1 and L2 function in posterior temporal and parietal regions. In those studies, ESM was performed intra-operatively, and therefore used more closely spaced electrodes than those used in the present study. Serafini et al. (2008), examined a pediatric patient undergoing English visual naming, Hebrew visual naming, English reading, and Hebrew reading and demonstrated single-task regions, single-language regions, as well as regions involved in both tasks and both languages using extra-operative ESM.

One of our patients demonstrated naming inhibition in response to stimulation of dominant inferior temporal region, consistent with the findings of several previous studies that also demonstrated language inhibition in the dominant basal temporal region during ESM (referred to as the basal temporal language area or BTLA) in epilepsy patients with seizures originating from the dominant temporal lobe (Luders et al., 1986; Burnstine et al., 1990; Krauss et al., 1996). In this patient, the seizure-onset zone was also localized to the dominant temporal region.

\section{ECoG SPECTRAL MAPPING OF VISUAL OBJECT NAMING IN L1 AND L2}

Despite significant overlap, the spatial patterns of ECoG HGA differed between first and second language visual object naming in three patients. In two patients (Patients 1 and 3 ), all sites that were $\mathrm{HGA}(+)$ during L1 naming were also $\mathrm{HGA}(+)$ during L2 naming, while additional sites were $\mathrm{HGA}(+)$ during L2 naming alone. In Patient 2 , an equal number of sites were HGA(+) during L1 and L2 naming, but four sites were specific to L1 and four sites were specific to L2. In Patient 3a, bilateral sites were identified during both L1 and L2 naming, but these sites were not tested with ESM. Finally, in Patient 4, the same sites were HGA(+) for L1 and L2 naming.

Several previous studies using different functional imaging modalities demonstrated that second language processing requires more cortical resources than first language processing (Klein et al., 1994; Dehaene et al., 1997; Graff-Radford et al., 1997; Kim et al., 1997; Perani et al., 2003; Meschyan and Hernandez, 2006; Marian et al., 2007; Kovelman et al., 2008). Researchers have found that this difference in spatial distribution for L1 and L2 is lessened or is eliminated entirely if L2 is introduced in early childhood (Kim et al., 1997; Wartenburger et al., 2003). In the current study, all patients acquired their second language after the age of 6 years, and in two patients, we observed more $\mathrm{HGA}(+)$ sites during L2 naming than during L1 naming. Consistent with these findings, previous studies have suggested that a later age of acquisition can lead to an increase in cortical resources required for L2 processing compared to L1 processing (Kim et al., 1997; Wartenburger et al., 2003). However, this pattern was not demonstrated in two patients (Patients 2 and 4), in whom ECoG spectral mapping did not reveal any differences in the number of $\mathrm{L} 1$ and $\mathrm{L} 2$ naming sites. In fact, naming sites were identical for L1 and L2 in Patient 4.

ECoG spectral mapping of L1 and L2 naming in Patient 2 showed a different pattern of $\mathrm{HGA}(+)$ electrodes in that there was an equal number of $\mathrm{HGA}(+)$ sites during L1 and L2 naming, with partial overlap within the perisylvian, prefrontal, parietal, and posterior basal temporal regions. This patient's performance on the BNT in L2 and in other neuropsychological measures of verbal performance in L2 was superior to those of Patients 1 and 3, indicating an overall higher level of proficiency in L2 compared to the other patients studied. Similar findings have been reported during ESM studies of patients where the number of electrodes involved in L1 and L2 language processing were equal despite incomplete overlap of the involved cortical regions (Graff-Radford et al., 1997; Roux and Tremoulet, 2002). Wartenburger et al. (2003) have shown that not only age of acquisition, but also level of proficiency impacts the overlap between cortical regions responsible for processing L1 and L2. In this patient, cortical regions were identified that were $\mathrm{HGA}(+)$ for L1 only, supporting the view that in some instances, neural networks responsible for $\mathrm{L} 1$ processing can be distinct from those for L2 (Perani et al., 1998).

In Patient 3a, bilateral HGA (+) sites were detected during both L1 and L2 visual object naming. A meta-analysis of 66 behavioral studies of bilingual adults performed by Hull and Vaid (2007) revealed that bilinguals that acquired both first and second languages prior to the age of 7 years show evidence of bilateral hemispheric involvement in language processing for both languages, while patients that acquired a second language after 6 years of age demonstrated dominant hemisphere lateralization for both languages. Patient 3 was introduced to English prior to age 7 years, which could account in part for the bilateral activation demonstrated. Additional fMRI and event-related potential studies have also demonstrated bilateral language function in some right-handed bilingual individuals (Dehaene et al., 1997; Cheung et al., 2006). Functional MRI and ECoG spectral mapping are both activation-based techniques that can detect augmentation of neural activity in homologous regions of the non-dominant hemisphere (such as visual association areas, articulatory motor regions, and auditory regions), which may also help explain these findings. Cortical sampling in our other patients was unilateral and therefore, no conclusions can be drawn regarding the potential laterality of cortical activation during L1 and L2 using ECoG spectral mapping in these patients.

To date, only two case studies have directly compared language mapping with ECoG spectral mapping of HGA in different language modalities. Crone et al. (2001) compared ECoG HGA during visual object naming, word reading, and word repetition in spoken English to signed responses using American Sign Language. Consistent with the very different output modalities of these two languages, spoken responses produced gamma activity in motor cortex within the tongue and mouth regions while sign language responses produced gamma activity in the hand regions of the 
motor strip. In some instances, letter spelling was used for some words in American Sign Language, so the languages themselves that were tested were not entirely different, only the output modalities. Tanji et al. (2005) measured HGA (80-120 Hz) during a lexicaldecision task in a patient with bilateral lateral and basal temporal subdural grids. The lexical-decision task consisted of two written forms of Japanese, kanji and kana, and the patient was presented with words and pseudo-words in each form. Technically, these were not distinct languages, but distinct written scripts within the Japanese writing system. The authors found a significant difference in the magnitude of HGA between kanji and kana words and between words and pseudo-words. They concluded that HGA is a valid measure of cortical activation in the basal temporal regions, and our findings support these conclusions.

\section{ECoG SPECTRAL MAPPING VERSUS ESM}

In the present study, ESM identified no differences in the cortical representations of L1 and L2 visual object naming in two of four patients, while ECoG spectral analysis revealed electrodes with HGA exclusively during L1 and/or L2 naming in three patients. Furthermore, ESM and ECoG spectral mapping revealed different language areas in all patients tested. Reasons for these disparities could include: (1) ESM is dictated by clinical necessity, so not all regions shown to contain $\mathrm{HGA}(+)$ sites were tested with ESM, (2) ESM stimulates pairs of electrodes and therefore, only one electrode within the pair may be responsible for producing cortical inhibition at a given site (Nathan et al., 1993), (3) ECoG spectral mapping is an activation procedure, so not all $\mathrm{HGA}(+)$ sites are necessarily essential for language function, (4) mapping language with ESM can at times produce equivocal or difficult to interpret results and can be influenced by patient motivation at the time of testing, and (5) when ESM produces after-discharges, seizures, or pain, testing is aborted and language function at those sites cannot be assessed.

Studies of language mapping using ECoG HGA have directly compared ECoG language mapping to ESM in left-hemisphere dominant epilepsy patients undergoing intracranial mapping for surgical planning. Sinai et al. (2005a) compared the spatial distribution of functional maps derived from ECoG HGA and ESM during visual object naming alone and found a specificity of 78\% but only a modest sensitivity of $38 \%$. When including a comparison of mouth-related motor function, the specificity and sensitivity increased to 84 and 43\%, respectively. Towle et al. (2008) investigated ECoG HGA during word repetition and word memory tasks and demonstrated a sensitivity of $63 \%$ and a specificity of $57 \%$ for ECoG high gamma mapping compared to ESM. In a more recent study, Sinai et al. (2009) demonstrated high spatial concordance between ESM and HGA during auditory perception of tones and speech with a specificity of $98 \%$, a sensitivity of $67 \%$, and a positive predictive value of $67 \%$. In addition, Thampratankul et al. (2010) recently identified activated areas with ECoG spectral mapping of HGA that were not appreciated with ESM.

\section{POST-OPERATIVE OUTCOMES}

Three of four patients presented here had a post-operative decline in naming performance predicted by ECoG spectral mapping but not by ESM. In one patient, a portion of the dominant anterior temporal region was resected and although this region was not exhaustively sampled by subdural electrodes, four electrodes within this region were evaluated by ESM and were determined not to contain eloquent language cortex. However, we observed significant HGA during naming in L2 only within the same region that was ultimately resected. The patient experienced a measurable decline in only L2 naming performance immediately post-operatively with preservation of L1 naming. These findings were somewhat surprising because naming does not typically localize to the dominant anterior temporal region and suggests potentially that L2 language reorganization may have occurred as a result of the location of the seizure focus also within the dominant temporal lobe. The differential decline in L2 but not L1 naming cannot be explained solely by post-operative stress and fatigue, or medication effect since L1 and L2 testing was performed in the same testing session and the patient did not perform more poorly on later test items. If decline in naming performance was due to removal of the dominant hippocampus (Hamberger et al., 2010), a decline in naming performance in both L1 and L2 would be expected. These findings suggest that in this case, ECoG spectral mapping may have provided a more accurate map of language function than ESM and also accurately identified a L2-specific cortical region.

When comparing these findings to previous studies, Tripathi et al. (2010) demonstrated the use of ECoG to predict post-operative clinical outcome following epilepsy surgery, but this did not include measures of language function. Sinai et al. (2005a) previously reported the post-operative L2 results for Patient 2 as one of a series of 13 patients that underwent ESM and ECoG spectral mapping of visual object naming in L2 only. However, this is the first study of which we are aware, that demonstrates post-operative language decline in only one of two languages, predicted by ECoG spectral mapping but not by ESM. Further studies are necessary to determine whether long-term post-operative outcomes more closely reflect the results of ESM or ECoG spectral mapping.

\section{METHODOLOGICAL CONSIDERATIONS}

This preliminary study demonstrates the feasibility of mapping naming in multiple languages with ECoG spectral mapping. However, there were several important limitations to this study. We have interpreted our findings in relation to those in patients that were truly "bilingual" in that they had equal fluency in two languages. There were inadequate data available to indicate whether our patients were equally fluent. However, all our patients were sufficiently fluent in L1 and L2 to use them in regular and meaningful conversations, and loss of either would have produced a definite negative impact on their daily lives and interactions with others. Normative data comparing performance on the BNT in English and Spanish as well as English and Greek bilinguals indicate that naming performance is significantly better in English than in Spanish or Greek (Kohnert et al., 1998; Patricacou et al., 2007), which may have been a confounding factor for Patients 3 and 4 . Also, studies have indicated that bilinguals perform better when tasks include pictures with cognate names (e.g., "dart" in English and "dardo" in Spanish), and this was not controlled for when comparing L1 and L2 naming using the BNT (Gollan et al., 2007). No normative data comparing performance on the BNT in Igbo or Italian was available. In addition, for the majority of studies reporting normative data on the BNT, the mean level of education was higher than in the 
patients reported here, which can account for the wide variability in $Z$-scores calculated across studies. Differences in task difficulty and relative L1 and L2 naming performance could theoretically impact localization or the extent of cortical recruitment. Finally, the order of stimulus presentation was not randomized in Patients 1 and 2, whose data were reviewed retrospectively.

Cultural differences regarding word frequency and complexity in different languages may have also impacted the level of relative L1 and L2 task difficulty in each patient. Italian and Spanish are romance languages, and Italian, Spanish, Greek and English are all Indo-European languages, while Igbo is a Niger-Congo tonal language and therefore most distinct from the other languages studied. In addition, there are other important differences in these languages with regard to prosody, syntax, and phonology and studies suggest that these differences can impact hemispheric representation and regional localization of different languages (Luke et al., 2002; Cheung et al., 2006).

In this experimental design, as with all studies of epilepsy patients undergoing intracranial monitoring, subdural electrode placement was dictated by clinical necessity and was not necessarily ideal for providing adequate coverage of eloquent language areas. This significantly limited the number of patients that were appropriate to be studied. In addition, resections included cortical regions not tested with ESM or ECoG spectral mapping that theoretically could have contained eloquent cortex. Finally, one recent study by Cheung et al. (2006) using fMRI showed that Chinese-English bilingual patients with temporal lobe epilepsy may have a different pattern of language lateralization than normal bilingual controls (Cheung et al., 2006).

Future studies are necessary to understand the impact of a seizure focus near eloquent cortex on language localization in multilinguals, and the contributions of proficiency, age of acquisition of languages, and age of seizure-onset. This further emphasizes the need to map all learned languages in epilepsy patients undergoing surgery near suspected language cortex. In addition, future studies

\section{REFERENCES}

Abutalebi, J. (2008). Neural aspects of second language representation and language control. Acta Psychol. (Amst.) $128,466-478$.

Aglioti, S., Beltramello, A., Girardi, F., and Fabbro, F. (1996). Neurolinguistic and follow-up study of an unusual pattern of recovery from bilingual subcortical aphasia. Brain 119, 1551-1564.

Aglioti, S., and Fabbro, F. (1993). Paradoxical selective recovery in a bilingual aphasic following subcortical lesions. Neuroreport 4, 1359-1362.

Alvarez, R.P., Holcomb, P. J., and Grainger, J. (2003). Accessing word meaning in two languages: an event-related brain potential study of beginning bilinguals. Brain Lang. 87, 290-304.

Anderson, J. M., Gilmore, R., Roper, S., Crosson, B., Bauer, R. M., Nadeau, S. Beversdorf, D. Q., Cibula, J., Rogish, M. 3rd, Kortencamp, S., Hughes, J. D., Gonzalez Rothi, L. J., and Heilman, K. M. (1999). Conduction aphasia and

should incorporate additional language tasks, as naming alone does not provide a comprehensive map of language localization (Roux et al., 2004; Hamberger, 2007).

\section{CONCLUSION}

Visual object naming using ECoG spectral mapping of first and second languages using HGA revealed shared as well as distinct regions. In two of four patients, more cortical regions revealed HGA during second language naming than first language naming. Therefore, mapping of function in L2 may be crucial in avoiding naming deficits. However, L1 mapping is also necessary given that L1-specific regions were also identified. Three of four patients presented here experienced a post-operative decline in naming performance predicted by ECoG spectral mapping but not by ESM. In one patient, a left temporal resection included a region of cortex involved in visual object naming in L2 based on ECoG spectral mapping but not ESM, and the patient exhibited an isolated naming deficit in L2 (but not L1) when assessed the day following surgery. ECoG spectral mapping of HGA may therefore complement ESM when mapping language function in multilingual patients.

\section{ACKNOWLEDGMENTS}

We thank the research participants who made this study possible. We also wish to acknowledge Juan Roberto Perilla, who helped with electrode co-registration and image reconstructions used for illustration, and Noelle Stewart, Rebecca Fisher, Viktar Kanasevich, and Karen Walters for administering ESM. We thank Dr. Frederick Lenz for performing all neurosurgical procedures. Supported by the Epilepsy Foundation (grant Research and Training Fellowships for Clinicians to Mackenzie C. Cervenka), National Institutes of Neurological Disorders and Stroke (grant R01-NS040596 to Nathan E. Crone), and National Institutes of Health - National Institute on Deafness and Other Communication Disorders (grants R01DC05645 and K24-DC010028 to Dana F. Boatman-Reich).

speech discrimination in normal and impaired listeners. J. Neurosci. 25 5475-5480.

Boatman-Reich, D., Franaszczuk, P. J., Korzeniewska, A., Caffo, B., Ritzl, E. K., Colwell, S., and Crone, N. E. (2010). Quantifying auditory eventrelated responses in multichannel human intracranial recordings. Front. Comput. Neurosci. 4, 4.

Brandt, J., and Benedict, R. H. B. (2001). Hopkins Verbal Learning Test-Revised. Lutz: Psychological Assessment Resources, Inc.

Brown, E. C., Rothermel, R., Nishida, M., Juhasz, C., Muzik, O., Hoechstetter, K., Sood, S., Chugani, H. T., and Asano, E. (2008). In vivo animation of auditory-language-induced gamma-oscillations in children with intractable focal epilepsy. Neuroimage 41, 1120-1131.

Burnstine, T. H., Lesser, R. P., Hart, J. Jr., Uematsu, S., Zinreich, S. J., Krauss, G. L., Fisher, R. S., Vining, E. P., and
Gordon, B. (1990). Characterization of the basal temporal language area in patients with left temporal lobe epilepsy. Neurology 40, 966-970.

Caramia, M. D., Cicinelli, P., Paradiso, C., Mariorenzi, R., Zarola, F., Bernardi, G., and Rossini, P.M. (1991). 'Excitability' changes of muscular responses to magnetic brain stimulation in patients with central motor disorders. Electroencephalogr. Clin. Neurophysiol. 81, 243-250.

Ceponiene, R., Shestakova, A., Balan, P., Alku, P., Yiaguchi, K., and Naatanen, R. (2001). Children's auditory eventrelated potentials index sound complexity and "speechness". Int. J. Neurosci. 109, 245-260.

Chee, M. W. (2009). fMR-adaptation and the bilingual brain. Brain Lang. 109, 75-79.

Chernigovskaya, T. V., Balonov, L. J., and Deglin, V. L. (1983). Bilingualism and brain functional asymmetry. Brain Lang. 20, 195-216. 
Cheung, M.-C., Chan, A. S., Chan, Y.-L., and Lam, J. M. K. (2006). Language lateralization of Chinese-English bilingual patients with temporal lobe epilepsy: a functional MRI study. Neuropsychology 20, 589-597.

Conboy, B. T., and Mills, D. L. (2006). Two languages, one developing brain: event-related potentials to words in bilingual toddlers. Dev. Sci. 9, F1-F12.

Crone, N. E. (2000). "Functional mapping with ECoG spectral analysis," in Neocortical Epilepsies, eds P. D. Williamson, A. M. Siegel, D. W. Roberts, V. M. Thadani, and M. S. Gazzaniga (Philadelphia: Lippincott Williams \& Wilkins)

Crone, N. E., Hao, L., Hart, J. Jr., Boatman, D., Lesser, R.P., Irizarry, R., and Gordon, B. (2001). Electrocorticographic gamma activity during word production in spoken and sign language. Neurology 57, 2045-2053.

Crone, N. E., Miglioretti, D. L., Gordon, B., and Lesser, R. P. (1998a). Functional mapping of human sensorimotor cortex with electrocorticographic spectral analysis. II. Event-related synchronization in the gamma band. Brain 121, 2301-2315.

Crone, N. E., Miglioretti, D. L., Gordon, B. Sieracki, J.M., Wilson, M. T., Uematsu, S., and Lesser, R. P. (1998b). Functional mapping of human sensorimotor cortex with electrocorticographic spectral analysis. I. Alpha and beta event-related desynchronization. Brain 121, 2271-2299.

Crone, N.E.,Sinai,A.S., and Korzeniewska, A. (2006). High-frequency gamma oscillations and human brain mapping with electrocorticography. Prog. Brain Res. 159, 279-302.

Dehaene, S., Dupoux, E., Mehler, J., Cohen, L., Paulesu, E., Perani, D., van de Moortele, P. F., Lehericy, S., and Le Bihan, D. (1997). Anatomical variability in the cortical representation of first and second language. Neuroreport 8, 3809-3815.

Durka, P. J. (2006). Time-frequency microstructure and statistical significance of ERD and ERS. Prog. Brain Res. 159, 121-133.

Durka, P. J., Zygierewicz, J., Klekowicz, H., Ginter, J., and Blinowska, K. J. (2004). On the statistical significance of event-related EEG desynchronization and synchronization in the timefrequency plane. IEEE Trans. Biomed. Eng. 51, 1167-1175.

Fabbro, F. (2001). The bilingual brain: bilingual aphasia. Brain Lang. 79, 201-210.

Franaszczuk, P. J., Bergey, G. K., Durka, P. J., and Eisenberg, H. M. (1998). Timefrequency analysis using the matching pursuit algorithm applied to seizures originating from the mesial tem- poral lobe. Electroencephalogr. Clin. Neurophysiol. 106, 513-521.

French, R. M., and Jacquet, M. (2004). Understanding bilingual memory: models and data. Trends Cogn. Sci. (Regul. Ed.) 8, 87-93.

Genesee, F., Nicoladis, E., and Paradis, J. (1995). Language differentiation in early bilingual development. J. Child Lang. 22, 611-631.

Giussani, C., Roux, F.E.,Lubrano, V., Gaini, S. M., and Bello, L. (2007). Review of language organisation in bilingual patients: what can we learn from direct brain mapping? Acta Neurochir. (Wien) 149, 1109-1116; Discussion 1116.

Gollan, T. H., Fennema-Notestine, C., Montoya, R. I., and Jernigan, T. L. (2007). The bilingual effect on Boston Naming Test performance. J. Int. Neuropsychol. Soc. 13, 197-208.

Gomez-Tortosa,E., Martin, E. M., Gaviria, M., Charbel, F., and Ausman, J. I. (1995). Selective deficit of one language in a bilingual patient following surgery in the left perisylvian area. Brain Lang. 48, 320-325.

Goodglass, H., Kaplan, E., and Weintraub, S. (1983). Boston Naming Test. Philadelphia: Lea and Febiger.

Graff-Radford, N. R., Lin, S.-C., Brazis, P. W., Bolling, J. P., Liesegang, T. J., Lucas, J. A., Uitti, R. J., and O'Brien, P. C. (1997). Tropicamide eyedrops cannot be used for reliable diagnosis of Alzheimer's disease. Mayo Clin. Proc. 72, 495-504.

Hamberger,M.J.(2007). Cortical language mapping in epilepsy: a critical review. Neuropsychol. Rev. 17, 477-489.

Hamberger, M. J., Goodman, R. R. Perrine, K., and Tamny, T. (2001). Anatomic dissociation of auditory and visual naming in the lateral temporal cortex. Neurology 56, 56-61.

Hamberger, M. J., Seidel, W.T., Goodman, R. R. and McKhann, G. M. 2nd. (2010). Does cortical mapping protect naming if surgery includes hippocampal resection? Ann. Neurol. 67, 345-352.

Holtzheimer, P., Fawaz, W., Wilson, C. and Avery, D. (2005). Repetitive transcranial magnetic stimulation may induce language switching in bilingual patients. Brain Lang. 94, 274-277.

Hull, R., and Vaid, J. (2007). Bilingual language lateralization: a metaanalytic tale of two hemispheres. Neuropsychologia 45, 1987-2008.

Ino, T., Nakai, R., Azuma, T., Kimura, T. and Fukuyama, H. (2009). Recognition and reading aloud of kana and kanji word: an fMRI study. Brain Res. Bull. 78, 232-239.

Kaplan, E., Goodglass, H., and Weintraub, S. (2001). Boston Naming Test. Austin: Pro-Ed, Inc

Khateb, A., Abutalebi, J., Michel, C. M. Pegna, A. J., Lee-Jahnke, H., and
Annoni, J.-M. (2007). Language selection in bilinguals: a spatio-temporal analysis of electric brain activity. Int J. Psychophysiol. 65, 201-213.

Kho, K. H., Duffau, H., Gatignol, P. Leijten, F. S. S., Ramsey, N. F., Rijen, P. C. v., and Rutten, G.-J. M. (2007) Involuntary language switching in two bilingual patients during the Wada test and intraoperative electrocortical stimulation. Brain Lang. 101, 31-37.

Kim, K. H., Relkin, N. R., Lee, K. M., and Hirsch, J. (1997). Distinct cortical areas associated with native and second languages. Nature 388, 171-174.

Klein, D., Milner, B., Zatorre, R. J., Meyer, E., and Evans, A.C. (1995). The neural substrates underlying word generation: a bilingual functional-imaging study. Proc. Natl. Acad. Sci. U.S.A. 92 2899-2903.

Klein, D., Zatorre, R. J., Milner, B., Meyer, E., and Evans, A. C. (1994). Left putaminal activation when speaking a second language: evidence from PET Neuroreport 5, 2295-2297.

Kohnert, K. J., Hernandez, A.E., and Bates, E. (1998). Bilingual performance on the Boston Naming Test: preliminary norms in Spanish and English. Brain Lang. 65, 422-440.

Kovelman, I., Shalinsky, M. H., Berens, M S., and Petitto, L. A. (2008). Shining new light on the brain's "bilingual signature": a functional Near Infrared Spectroscopy investigation of semantic processing. Neuroimage 39, 1457-1471.

Krauss, G. L., Fisher, R., Plate, C., Hart, J., Uematsu, S., Gordon, B., and Lesser, R. P. (1996). Cognitive effects of resecting basal temporal language areas. Epilepsia 37, 476-483.

Leinonen, A., Laine, M., Laine, M., and Krause, C. M. (2007). Electrophysiological correlates of memory processing in early FinnishSwedish bilinguals. Neurosci. Lett. 416, 22-27.

Lesser, R. P., Lüders, H., Klem, G., Dinner, D. S., Morris, H. H., and Hahn, J. (1984). Cortical afterdischarge and functional response thresholds: results of extraoperative testing. Epilepsia 25 615-621.

Lesser, R. P., Lüders, H., Klem, G., Dinner, D. S., Morris, H. H., Hahn, J. F., and Wyllie,E. (1987). Extraoperative cortical functional localization in patients with epilepsy. J. Clin. Neurophysiol. 4, 27-53.

Lubrano, V., Roux, F. E., and Demonet, J. F (2004). Writing-specific sites in frontal areas: a cortical stimulation study. $J$. Neurosurg. 101, 787-798.

Lucas, T. H. 2nd, McKhann, G. M. 2nd, and Ojemann, G.A. (2004). Functional separation of languages in the bilin- gual brain: a comparison of electrical stimulation language mapping in 25 bilingual patients and 117 monolingual control patients. J. Neurosurg. 101, 449-457.

Luders, H., Lesser, R. P., Hahn, J., Dinner, D. S., Morris, H., Resor, S., and Harrison, M. (1986). Basal temporal language area demonstrated by electrical stimulation. Neurology 36 , 505-510.

Luke, K. K., Liu, H. L., Wai, Y. Y., Wan, Y. L., and Tan, L. H. (2002). Functional anatomy of syntactic and semantic processing in language comprehension. Hum. Brain Mapp. 16, 133-145.

Mallat, S., and Zhang, Z. (1993). Matching pursuit with time-frequency dictionaries. IEEE Trans. Signal Process. 41, 3397-3415.

Marangolo, P., Rizzi, C., Peran, P., Piras, F., and Sabatini, U. (2009). Parallel recovery in a bilingual aphasic: a neurolinguistic and fMRI study. Neuropsychology 23, 405-409.

Marian, V., Shildkrot, Y., Blumenfeld, H. K., Kaushanskaya, M., Faroqi-Shah, Y., and Hirsch, J. (2007). Cortical activation during word processing in late bilinguals: similarities and differences as revealed by functional magnetic resonance imaging. J. Clin. Exp. Neuropsychol. 29, 247-265.

Marian, V., Spivey, M., and Hirsch, J. (2003). Shared and separate systems in bilingual language processing: converging evidence from eyetracking and brain imaging. Brain Lang. 86, 70-82.

Meschyan, G., and Hernandez, A. E. (2006). Impact of language proficiency and orthographic transparency on bilingual word reading: an fMRI investigation. Neuroimage 29, 1135-1140.

Mitrushina, M., Boone, K. B., Razani, J., and D'Elia, L. F. (2005). Handbook of Normative Data for Neuropsychological Assessment. New York: Oxford University Press.

Moreno, E. M., and Kutas, M. (2005). Processing semantic anomalies in two languages: an electrophysiological exploration in both languages of Spanish-English bilinguals. Cogn. Brain Res. 22, 205-220.

Moritz-Gasser, S., and Duffau, H. (2009). Evidence of a large-scale network underlying language switching: a brain stimulation study. J. Neurosurg. 111, 729-732.

Nathan, S. S., Sinha, S. R., Gordon, B. Lesser, R. P., and Thakor, N. V. (1993). Determination of current density distributions generated by electrical stimulation of the human cerebral cortex. Electroencephalogr. Clin. Neurophysiol. 86, 183-192. 
Ojemann, G. A. (1979). Individual variability in cortical localization of language. J. Neurosurg. 50, 164-169.

Ojemann, G. A., and Whitaker, H. A. (1978). The bilingual brain. Arch. Neurol. 35, 409-412.

Patricacou, A., Psallida, E., Pring, T., and Dipper, L. (2007). The Boston Naming Test in Greek: normative data and the effects of age and education on naming. Aphasiology 21, 1157-1170.

Perani, D., and Abutalebi, J. (2005). The neural basis of first and second language processing. Curr. Opin. Neurobiol. 15, 202-206.

Perani, D., Abutalebi, J., Paulesu, E., Brambati, S., Scifo, P., Cappa, S. F., and Fazio, F. (2003). The role of age of acquisition and language usage in early, high-proficient bilinguals: an fMRI study during verbal fluency. Hum. Brain Mapp. 19, 170-182.

Perani, D., Paulesu, E., Galles, N. S., Dupoux, E., Dehaene, S., Bettinardi, V., Cappa, S. F., Fazio, F., and Mehler, J. (1998). The bilingualbrain. Proficiency and age of acquisition of the second language. Brain 121, 1841-1852.

Ponton, M. O., Satz, P., Herrera, L., Ortiz, F., Urrutia, C. P., Young, R., D’Elia, L. F., Furst, C. J., and Namerow, N. (1996). Normative data stratified by age and education for the Neuropsychological Screening Battery for Hispanics (NeSBHIS): initial report. J. Int. Neuropsychol. Soc. 2, 96-104.

Pouratian, N., Cannestra, A. F., Bookheimer, S. Y., Martin, N. A., and Toga, A. W. (2004). Variability of intraoperative electrocortical stimulation mapping parameters across and within individuals. J. Neurosurg. 101, 458-466.

Rapport, R. L., Tan, C. T., and Whitaker, H. A. (1983). Language function and dysfunction among Chinese- and English-speaking polyglots: cortical stimulation, Wada testing, and clinical studies. Brain Lang. 18, 342-366.

Ray, S., Jouny, C.C., Crone, N.E., Boatman, D., Thakor, N. V., and Franaszczuk, P. J. (2003).Human ECoG analysis during speech perception using matching pursuit: a comparison between stochastic and dyadic dictionaries. IEEE Trans. Biomed. Eng. 50, 1371-1373.

Reiterer, S., Hemmelmann, C. Rappelsberger, P., and Berger, M. L. (2005). Characteristic functional networks in high- versus low-proficiency second language speakers detected also during native language processing: an explorative EEG coherence study in 6 frequency bands. Cogn. Brain Res. 25, 566-578.

Rey, A. (1964). L'examen clinique en psychologie. Paris: Presses Universitaires de France.

Roberts, P. M., Garcia, L. J., Desrochers, A., and Hernandez, D. (2002). English performance of proficient bilingual adults on the Boston Naming Test. Aphasiology 16, 634-645.

Rosselli, M.,Ardila, A., Araujo, K., Weekes, V. A., Caracciolo, V., Padilla, M., and Ostrosky-Solis, F. (2000). Verbal fluency and repetition skills in healthy older Spanish-English bilinguals. Appl. Neuropsychol. 7, 17-24.

Roux, F.-E., Lubrano, V., Lauwers-Cances, V., Tremoulet, M., Mascott, C. R., and Demonet, J.-F. (2004). Intra-operative mapping of cortical areas involved in reading in mono- and bilingual patients. Brain 127, 1796-1810.

Roux, F. E., and Tremoulet, M. (2002). Organization of language areas in bilingual patients: a cortical stimulation study. J. Neurosurg. 97, 857-864.

Serafini, S., Gururangan, S., Friedman, A., and Haglund, M. (2008). Identification of distinct and overlapping cortical areas for bilingual naming and reading using cortical stimulation. Case report. J. Neurosurg. Pediatr. 1, 247-254.

Shestakova, A., Huotilainen, M., Ceponiene, R., and Cheour, M. (2003). Event-related potentials associated with second language learning in children. Clin. Neurophysiol. 114, 1507-1512.

Sinai, A., Bowers, C. W., Crainiceanu, C. M., Boatman, D., Gordon, B., Lesser, R. P., Lenz, F. A., and Crone, N. E. (2005a). Electrocorticographic high gamma activity versus electrical cortical stimulation mapping of naming. Brain 128, 1556-1570.

Sinai, A., Franaszczuk, P., and Crone, N. E. (2005b). Electrocorticographic spectral responses during auditory vs. visual lexical semantic processing. Epilepsia 46, 71-72.

Sinai, A., Crone, N. E., Wied, H. M. Franaszczuk, P. J., Miglioretti, D. and Boatman-Reich, D. (2009). Intracranial mapping of auditory perception: event-related responses and electrocortical stimulation. Clin. Neurophysiol. 120, 140-149.

Spreen, O., and Benton, A. L. (1977) Neurosensory Center Comprehensive Examination for Aphasia (NCCEA). Victoria: University of Victoria Neuropsychology Laboratory.

Tanji, K., Suzuki, K., Delorme, A. Shamoto, H., and Nakasato, N. (2005). High-frequency gammaband activity in the basal temporal cortex during picture-naming and lexical-decision tasks. J. Neurosci. 25, 3287-3293.

Thampratankul, L., Nagasawa, T., Rothermel, R., Juhasz, C., Sood, S., and Asano, E. (2010). Cortical gamma oscillations modulated by word association tasks: intracranial recording. Epilepsy Behav. 18, 116-118.

Towle, V. L., Yoon H.-A., Castelle, M. Edgar, C., Biassou, N. M., Frim, D. M., Spire, J.-P., and Kohrman, M. H. (2008). ECoG gamma activity during a language task: differentiating expressive and receptive speech areas. Brain 131, 2013-2027.

Tripathi, M., Garg, A., Gaikwad, S., Bal, C. S., Chitra, S., Prasad, K., Dash, H. H., Sharma, B. S., and Chandra, P. S. (2010). Intra-operative electrocorticography in lesional epilepsy. Epilepsy Res. 89, 133-141.

van Heuven, W. J., Schriefers, H., Dijkstra, T., and Hagoort, P. (2008). Language conflict in the bilingual brain. Cereb Cortex 18, 2706-2716.

Votaw, J. R., Faber, T. L., Popp, C. A., Henry, T. R., Trudeau, J. D., Woodard, J. L., Mao, H., Hoffman, J. M., and Song, A.W. (1999). A confrontational naming task produces congruent increases and decreases in PET and FMRI. Neuroimage 10, 347-356.

Walker, J.A., Quinones-Hinojosa, A., and Berger, M. S. (2004). Intraoperative speech mapping in 17 bilingual patients undergoing resection of a mass lesion. Neurosurgery 54, 113-118.

Wartenburger, I., Heekeren, H. R., Abutalebi, J., Cappa, S. F., Villringer, A., and Perani, D. (2003). Early setting of grammatical processing in the bilingual brain. Neuron 37, 159-170.

Wechsler, D. (1987). Wechsler Adult Intelligence Scale-Revised. San Antonio: The Psychological Corporation.

Wechsler, D. (1997). Wechsler Adult Intelligence Scale-Third Edition. San Antonio: The Psychological Corporation.

Wilkinson, G. S., and Robertson, G. J. (2006). Wide Range Achievement Test. Lutz: Psychological Assessment Resources, Inc.

Zygierewicz, J., Durka, P. J., Klekowicz, H., Franaszczuk, P. J., and Crone, N. E. (2005). Computationally efficient approaches to calculating significant ERD/ERS changes in the time-frequency plane. J. Neurosci. Methods $145,267-276$

Conflict of Interest Statement: The authors declare that the research was conducted in the absence of any commercial or financial relationships that could be construed as a potential conflict of interest.

Received: 30 July 2010; accepted: 23 January 2011; published online: 22 February 2011. Citation: Cervenka MC, Boatman-Reich DF, Ward J, Franaszczuk PJ and Crone NE (2011) Language mapping in multilingual patients: electrocorticography and cortical stimulation during naming. Front. Hum. Neurosci. 5:13. doi: 10.3389/ fnhum.2011.00013

Copyright (c) 2011 Cervenka, BoatmanReich, Ward, Franaszczuk and Crone. This is an open-access article subject to an exclusive license agreement between the authors and Frontiers Media SA, which permits unrestricted use, distribution, and reproduction in any medium, provided the original authors and source are credited. 